\title{
Coated stainless steel archwires' discoloration measured by computerized system (An in-vitro study)
}

\begin{abstract}
Abeer Basim Mahmood (1)
https://doi.org/10.26477/jbcd.v32i4.2911

\section{ABSTRACT}

Background: Aesthetic archwires are used to overcome the aesthetic problems of stainless steel wires but the color of the coating layer can be changed with time when exposed to oral environments. The aim of this study was to evaluate the degree of color change of different aesthetic archwires from different companies under different coloring solutions.

Materials and Methods: One hundred fifty samples of coated archwires from three companies (Highland, G\&H and Dany) were immersed in 5 solutions (artificial saliva, turmeric, tea, coffee and Miranda) to evaluate the degree of color changes after 7, 14 and 21 days using visible spectrophotometer. Data were collected and analyzed using one way ANOVA and post hoc Tukey's tests.

Results: Turmeric solution caused high color change than other solutions. Aesthetic archwires from Highland company showed the highest degree of color change than archwires from other companies.

Conclusions: Turmeric solution produced more discoloration than other solutions and the effects of these solutions are related to different chemical compositions of those solutions.

Keywords: Aesthetic archwires, staining drinks, Turmeric,Tea, Coffee, Miranda. (Received: 8/10/2019; Accepted: 4/11/2019)
\end{abstract}

\section{INTRODUCTION}

With the advent of increasing number of adults seeking orthodontic treatment, the development of orthodontic appliances with ample emphasis on esthetics coupled with optimal performance has become an essential goal or rather necessity of the day ${ }^{(1)}$.

The demand for esthetic orthodontic appliances has increased dramatically, creating a need for the so-called invisible orthodontic appliances like Invisalign, and lingual braces (2). However, esthetics of fixed labial appliances has also evolved by inclusion of ceramic brackets ${ }^{(3)}$, esthetic ligatures and tooth colored archwires ${ }^{(4)}$.

Esthetic archwire materials are basically a composite of two materials which can be broadly classified into two major groups; composite archwires and coated metallic archwires ${ }^{(5-7)}$.

The color stability of esthetic archwires during orthodontic treatment is clinically important. Any staining or discoloration or change in esthetic of patient will affect the cooperation and acceptance to his treatment. Color instability of these wires and exposure of the underlying metal is also often reported. It has been found that $25 \%$ of coating is lost in 33 days intra-orally; therefore, the wire becomes aesthetically degraded ${ }^{(8)}$.

Coating improves esthetics but has some disadvantages. The color tends to change with time coat as "un-durable", like other esthetic orthodontic products, and there are internal and external causes for the discoloration of esthetic archwires ${ }^{(9)}$.

(1) rofessor, Department of Orthodontics, College of Dentistry, University of Baghdad.

Corresponding author,dr_abeerbasim@yahoo.com
External discoloration can be caused by food dyes and colored mouth rinses. The type of coating material and its surface roughness play decisive roles in the extent of the discoloration caused by diverse substances. The amount of color change can be influenced by a number of factors including oral hygiene and water absorption $^{(10)}$.

Discoloration of archwires can be caused by food dyes or mouth washes. The daily consumption of tea, coffee and soft drinks promotes discoloration of these wires ${ }^{(11)}$, so this study was planned to compare the color stability of different brands of esthetic archwires immersed in artificial saliva, black tea, coffee, turmeric and Miranda.

\section{MATERIALS AND METHODS}

Epoxy-coated stainless steel archwire with a dimension of $0.019 \times 0.025$ inch were selected from three different companies (Highland metals, G\&H orthodontic and Dany).

A total of one hundred fifty segments (50 samples from each company) were prepared by cutting the preformed arch wires into two parts and placing ten parts of the coated archwires segments from each company in several solutions including: artificial saliva, black tea, Miranda, Coffee, Turmeric solution.

The solutions were replaced regularly to prevent the precipitation and change in concentration as follow:

- Black tea and coffee (three times daily)

- Miranda (two times daily)

- Turmeric (one time daily) 
The color change was assessed using a visible spectrophotometer after numbering the specimens of each subgroup from 1 to 10 for each solution by the marker which could not be removed by the solutions.

The samples were incubated in distilled water in glass container at $37^{\circ} \mathrm{C}$ for 24 hours using incubator. Baseline measurement was done to measure the light reflection of each specimen by visible spectrophotometer at visible wavelengths started from $300-700 \eta \mathrm{m}$ at $10 \eta \mathrm{m}$ intervals. Color measurements were repeated after 7 days (T1), 14 days (T2), and 21 days (T3) of immersion in the solution.

Before each measurement, samples were removed from the solution and rinsed with distilled water for 5 minutes. Excess water on the surfaces was removed with tissue papers and then left to dry.

\section{Statistical Analyses}

The data were analyzed using SPSS (Statistical Package of Social Science) version 24 (IBM Co., New York, USA). The statistical analyses included:

- Descriptive statistics including mean, standard deviation, maximum and minimum values.

- Inferential statistics: including: One-way analysis of variance (ANOVA) to test any statistically significant difference among groups followed by post hoc Tukey's honestly significant difference (HSD) to test any statistically significant differences between each two groups.

\section{RESULTS}

Tables 1-3 showed the descriptive statistics and comparison of the degree of color absorption and effect of different solution on coated archwires after 7, 14 and 21 days of immersion respectively.

The results revealed that the most potent solutions causing color change were the Turmeric and tea among brands and durations.

Generally, archwires from Highland company had the highest degree of color change followed by Dany and G\&H and the amount of color change increased with increased immersion time.

Tukey's HSD test (table 4) showed that the difference between each two groups as followed:

- For artificial saliva, there is no significant difference between Highland and G\&H after 21 days of archwires immersion.

- For the Turmeric solution, there are high significant differences among all groups for all duration of archwire immersion.

- High significant differences have also been found between groups of Coffee solution except between Highland and G\&H after 7 days and between Highland and Dany after 14 and 21 days of immersion.

- For the Tea solution, there were no significant differences between most groups except for Dany with Highland and G\&H with high significant differences between them.

- The least effective solution was Miranda for all archwires and among all durations with no significant differences between groups except for Dany with Highland and G\&H with Highland where there were significant differences between them.

Table 1: Descriptive statistics and comparison of the degree of color absorption after 7 days of immersion.

\begin{tabular}{|c|c|c|c|c|}
\hline \multirow{2}{*}{ Media } & \multirow{2}{*}{ Archwires } & Descriptive statistics & \multicolumn{2}{|c|}{ Comparison } \\
\hline & & \begin{tabular}{|l|l|} 
Mean & S.D. \\
\end{tabular} & & \\
\hline \multirow{3}{*}{ Turmeric } & Highland & \begin{tabular}{|l|l|l|l|}
0.690 & 0.0120 .67402 \\
\end{tabular} & \multirow{3}{*}{127.883} & \multirow{3}{*}{0.000} \\
\hline & $\mathbf{G \& H}$ & \begin{tabular}{|l|l|l|l|}
0.615 & 0.017 & 0.600 .641 \\
\end{tabular} & & \\
\hline & Dany & \begin{tabular}{|l|l|l|l|l|}
0.522 & 0.020 & 0.503 & 0.555 \\
\end{tabular} & & \\
\hline \multirow{3}{*}{ Tea } & Highland & \begin{tabular}{|l|l|l|l|l|} 
\\
\end{tabular} & \multirow{3}{*}{29.140} & \multirow{3}{*}{0.000} \\
\hline & G \& H & \begin{tabular}{|l|l|l|l|}
0.297 & 0.011 & 0.281 & 0.311 \\
\end{tabular} & & \\
\hline & Dany & \begin{tabular}{|l|l|l|l|}
0.350 .00444 & 0.355 \\
\end{tabular} & & \\
\hline \multirow{3}{*}{ Coffee } & Highland & \begin{tabular}{|l|l|l|l|}
0.497 & 0.009 & 0.489 & 0.510 \\
\end{tabular} & \multirow{3}{*}{253.324} & \multirow{3}{*}{0.000} \\
\hline & G\& H & \begin{tabular}{|l|l|l|l|}
0.492 & 0.007 & 0.485 & 0.500 \\
\end{tabular} & & \\
\hline & & \begin{tabular}{|l|l|l|l|l|}
0.408 & 0.005 & 0.400 & 0.411 \\
\end{tabular} & & \\
\hline \multirow{3}{*}{ Miranda } & Highland & \begin{tabular}{|c|c|c|c|} 
\\
\end{tabular} & \multirow{3}{*}{8.257} & \multirow{3}{*}{0.006} \\
\hline & G\& H & \begin{tabular}{|l|l|l|l|l|}
0.113 & 0.013 & 0.100 .132 \\
\end{tabular} & & \\
\hline & Dany & \begin{tabular}{|l|l|l|l|}
0.160 & 0.027 & 0.120 .190 \\
\end{tabular} & & \\
\hline
\end{tabular}


Table 2: Descriptive statistics and comparison of the degree of color absorption after 14 days of immersion.

\begin{tabular}{|c|c|c|c|c|}
\hline \multirow{2}{*}{ Media } & \multirow{2}{*}{ Archwire } & Descriptive statistics & \multicolumn{2}{|c|}{ Comparison } \\
\hline & & \begin{tabular}{|l|l|} 
Mean & S.D. \\
Min. Max.
\end{tabular} & F-test & p-value \\
\hline \multirow{3}{*}{ Turmeric } & Highland & $0.818|0.0180 .800| 0.844$ & \multirow{3}{*}{548.861} & \multirow{3}{*}{0.000} \\
\hline & $\mathbf{G ~ \& ~ H ~}$ & \begin{tabular}{|l|l|l|l|l|l|l|}
0.681 & 0.002 & 0.679 \\
\end{tabular} & & \\
\hline & Dany & \begin{tabular}{|l|l|l|l|}
0.578 & 0.008 & 0.570 .588 \\
\end{tabular} & & \\
\hline \multirow[t]{3}{*}{ Tea } & Highland & $|0.3890 .0080 .380| 0.400$ & \multirow{3}{*}{15.184} & \multirow{3}{*}{0.001} \\
\hline & G\& H & \begin{tabular}{|l|l|l|l|}
0.359 & 0.008 & 0.350 .371 \\
\end{tabular} & & \\
\hline & Dany & \begin{tabular}{|l|l|l|l|}
0.4021 & 0.390 & 0.440 \\
\end{tabular} & & \\
\hline \multirow{3}{*}{ Coffee } & Highland & $0.587|0.005| 0.581 \mid 0.592$ & \multirow{3}{*}{1.199} & \multirow{3}{*}{0.335} \\
\hline & G \& H & \begin{tabular}{|l|l|l|l|l|}
0.521 & 0.113 & 0.39512 \\
\end{tabular} & & \\
\hline & Dany & \begin{tabular}{|l|l|l|l|l|}
0.548 & 0.520 & 0.590 \\
\end{tabular} & & \\
\hline \multirow{3}{*}{ Miranda } & Highland & $|0.205| 0.0160 .190 \mid 0.230$ & \multirow{3}{*}{44.411} & \multirow{3}{*}{0.000} \\
\hline & \begin{tabular}{|l|}
$\mathbf{G} \& \mathbf{H}$ \\
\end{tabular} & $0.190 \mid 0.0080 .1820 .201$ & & \\
\hline & Dany & \begin{tabular}{|l|l|l|l|}
0.251 & 0.006 & 0.244 & 0.260 \\
\end{tabular} & & \\
\hline
\end{tabular}

Table 3: Descriptive statistics and comparison of the degree of color absorption after 21 days of immersion.

\begin{tabular}{|c|c|c|c|c|}
\hline \multirow{2}{*}{ Media } & \multirow{2}{*}{ Archwire } & \begin{tabular}{|l} 
Descriptive statistics \\
\end{tabular} & \multicolumn{2}{|c|}{ Comparison } \\
\hline & & \begin{tabular}{|l|l|} 
Mean & S.D. \\
Min. Max.
\end{tabular} & F-test & p-value \\
\hline \multirow{3}{*}{$\begin{array}{c}\text { Artificial } \\
\text { saliva }\end{array}$} & Highland & \begin{tabular}{|c|c|c|c|c|}
0.019 & 0.020 \\
\end{tabular} & \multirow{3}{*}{4.216} & \multirow{3}{*}{0.041} \\
\hline & & \begin{tabular}{|l|l|l|l|}
0.018 & 0.007 & 0.011 & 0.028 \\
\end{tabular} & & \\
\hline & Dan & \begin{tabular}{|l|l|l|l|}
0.004 & 0.007 & 0.017 \\
\end{tabular} & & \\
\hline \multirow{3}{*}{ Turmeric } & Highland & \begin{tabular}{|l|l|l|l|l|}
0.978 & 0.042 & 0.91020 \\
\end{tabular} & \multirow{3}{*}{91.019} & \multirow{3}{*}{0.000} \\
\hline & & \begin{tabular}{|c|c|c|c|}
0.850 & 0.024 & 0.820 & 0.880 \\
\end{tabular} & & \\
\hline & & & & \\
\hline \multirow{3}{*}{ Tea } & Hig & $0.491 \mid 0.0$ & \multirow{3}{*}{22.215} & \multirow{3}{*}{0.000} \\
\hline & & $|0.458| 0.003 \mid 0.4$ & & \\
\hline & & \begin{tabular}{|l|l|l|}
0.488 & $0.013 \mid 0.4$ \\
\end{tabular} & & \\
\hline \multirow{3}{*}{ Coffee } & Highland & \begin{tabular}{|l|l|l|l|}
0.687 & 0.009 & 0.680 \\
\end{tabular} & \multirow{3}{*}{39.044} & \multirow{3}{*}{0.000} \\
\hline & $\mathbf{G} \& \mathbf{H}$ & \begin{tabular}{|l|l|l|l|l|l|l|l|}
0.702 & 0.013 & 0.690 & 0.720 \\
\end{tabular} & & \\
\hline & & \begin{tabular}{|l|l|l|l|}
0.626 & 0.019 & 0.600 & 0.650 \\
\end{tabular} & & \\
\hline \multirow{3}{*}{ Miranda } & Highland & \begin{tabular}{|l|l|l|l|}
0.342 & 0.041 & 0.299 & 0.390 \\
\end{tabular} & \multirow{3}{*}{1.013} & \multirow{3}{*}{0.392} \\
\hline & & \begin{tabular}{|l|l|l|l|}
0.318 & 0.019 & 0.299 & 0.350 \\
\end{tabular} & & \\
\hline & & \begin{tabular}{|l|l|l|l|l|}
0.331 & 0.011 & 0.320 & 0.350 \\
\end{tabular} & & \\
\hline
\end{tabular}

Table 4: Tukey's HSD test after ANOVA test

\begin{tabular}{|c|c|c|c|c|c|}
\hline Media & Archw & vires & 7 days & 14 day & 21 days \\
\hline & & $\mathbf{G \& H}$ & - & - & 0.941 \\
\hline & & Dany & - & - & 0.049 \\
\hline & $G \& H$ & Dany & & & 0.047 \\
\hline & & $G \& H$ & 0.000 & 0.000 & 0.000 \\
\hline Turmeric & & \begin{tabular}{|l|} 
Dany \\
\end{tabular} & \begin{tabular}{|l|}
0.000 \\
\end{tabular} & 0.000 & 0.000 \\
\hline & $G \& H$ & Dany & \begin{tabular}{|l|l|}
0.000 \\
\end{tabular} & 0.000 & 0.000 \\
\hline & & $G \& H$ & 0.074 & 0.012 & 0.000 \\
\hline Tea & & Dany & 0.001 & 0.160 & 0.836 \\
\hline & G\& H & Dany & 0.000 & 0.000 & 0.000 \\
\hline & & $\mathbf{G} \& \mathbf{H}$ & 0.541 & 0.308 & 0.265 \\
\hline Coffee & & Dany & 0.000 & 0.644 & 0.000 \\
\hline & G \& H & Dany & 0.000 & 0.807 & 0.000 \\
\hline & & G\& H & \begin{tabular}{|l|l|} 
\\
\end{tabular} & 0.094 & 0.362 \\
\hline randa & & Dany & 0.028 & 0.000 & 0.815 \\
\hline & $G \& H$ & Dany & 0.006 & 0.000 & 0.708 \\
\hline
\end{tabular}




\section{DISCUSSION}

The visible spectrophotometer did not give any readings for the artificial saliva during the first two readings i.e. after 7 and 14 days with minimum readings after 21 days of archwire immersion.

All solutions altered the final color of the archwire specimens. In an ascending order, staining of the test specimens was as followed: artificial saliva, Miranda, tea, coffee and turmeric.

The present study showed differences in the degree of color changes for different types of aesthetic archwires from different companies and under the same solutions. This may be due to different chemical and physical compositions of the aesthetic archwires which need further researches to explore the accurate causative agents. The highest degree of color change was recorded with turmeric solution because of the high content of the gold-yellow coloring agent (curcumin) (12). The variation between the readings of coffee and tea solutions was related to the compositions of these solutions.

The caffeine content was differed between coffee and tea being high in coffee $(70 \mathrm{mg}$ in 237 $\mathrm{ml}$.) as compared to its contents in tea (40 $\mathrm{mg}$ in $237 \mathrm{ml}.)^{(13,14)}$.

The least degree of color change was found with Miranda solution due to the presence of ascorbic and citric acids that may have cleaning effect as compared to tea and coffee that showed some precipitation which increased the staining effect ${ }^{(15)}$.

\section{CONCLUSION}

- Turmeric solution had the highest effect on color stability.

- The amount of color change increased with increasing immersion time.

- Coffee solution produced discoloration more than tea which may be related to the amount of caffeine materials.

- Miranda has the least effect due to the cleaning effect of acidic content.

\section{REFERENCES}

1. Lagravere MO, Flores-Mir C. The treatment effects of Invisalign orthodontic aligners: a systematic review. J Am Dent Assoc. 2005; 136:1724-9.

2. Ye L, Kula KS. Status of lingual orthodontics. World J Orthod. 2006; 7: 361-8.

3. Lee YK. Colour and translucency of tooth-coloured orthodontic brackets. Eur J Orthod. 2008; 30: 205-10.

4. Feu D, Catharino F, Duplat CB, Capelli JJ. Esthetic perception and economic value of ort hodontic appliances by lay Brazilian adults. Dental Press J Orthod. 2012; 17:102-14.

5. Elayyan F, Silikas N, Bearn D. Mechanical properties of coated superelastic archwires in conventional and self-ligating orthodontic brackets. Am J Orthod Dentofacial Orthop. 2010; 137: 213-7.

6. Kusy RP. The future of orthodontic materials: the long-term view. Am J Orthod Dentofacial Orthop. 1998; 113: 91-5.

7. Kusy RP. A review of contemporary archwires: their properties and characteristics. Angle Orthod. 1997; 67: 197-208.

8. Li Y, Hu B, Liu Y, Ding G, Zhang C, Wang S. The effects of fixed orthodontic appliances on saliva flow rate and saliva electrolyte concentrations. J Oral Rehabil. 2009; 36: 781-5.

9. Lim KF, Lew KK, Toh SL. Bending Stiffness of Two Aesthetic Orthodontic Archwires: An in Vitro Comparative Study. Clin Mater. 1994; 16: 63-71.

10. McCabe JF. Anderson's applied dental materials. $6^{\text {th }}$ ed. Blackwell Scientific Publications; 1985. Pp.9, 43, 46, 65-66, 68.

11. Proffit WR. Contemporary Orthodontics. $3^{\text {rd }}$ ed. St. Louis: Mosby Company; 2000.

12. Faltermeier A, Rosentritt M, Reicheneder C, Behr M. Discoloration of orthodontic adhesives caused by food dyes and ultraviolet light. Eur J Orthod. 2008; 30: 8993.

13. Lagravere MO, Flores-Mir C. The treatment effects of Invisalign orthodontic aligners: a systematic review. J Am Dent Assoc. 2005; 136: 1724-9.

14. Ye L, Kula KS. Status of lingual orthodontics. World J Orthod. 2006; 7: 361-8.

15. Lee YK. Colour and translucency of tooth-coloured orthodontic brackets. Eur J Orthod. 2008; 30: 205-10.

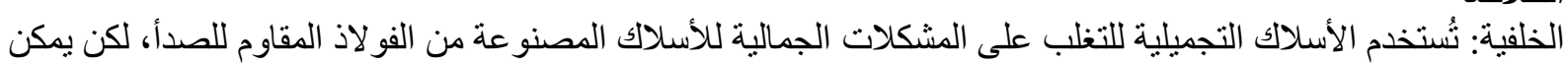

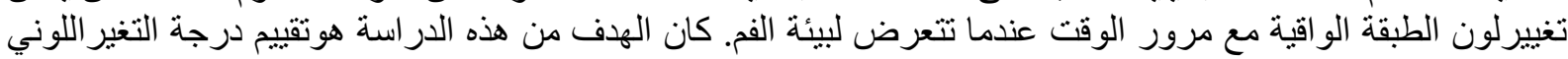

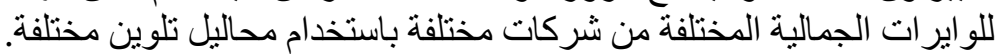

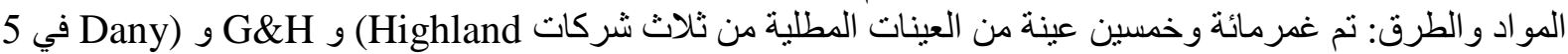

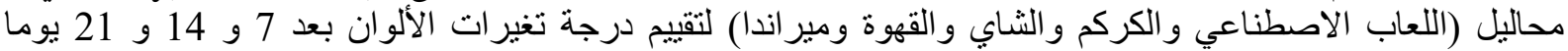

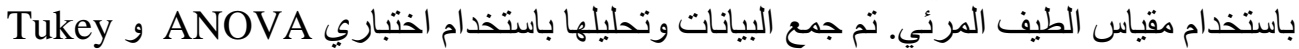
النتائج: تسبب حل الكركم فيتغير اللون عالي بالي بالمقارنة مع المحاليل الأخرى. أظهرت الكياري العينات الجمالية من شركةهايلاند

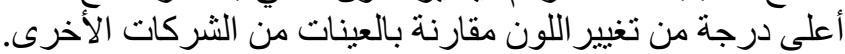
الاستنتاجات: أنتج محلول الكركم تلونًا أكثرمن المحاليل الأخرى ونرتبط الثرى آثار هذه المحاليل بتركيبات كيميائية مختلفة لتلك المحاليل.
} 